\title{
Spectinomycin in the treatment of gonorrhoea
}

A Gil-Setas (agilseta@navarra.es) ${ }^{1}$, A Navascués-Ortega ${ }^{1}$, X Beristain $^{1}$

1. Microbiology, Navarre Health Department. Pamplona, Spain

Citation style for this article:

Citation style for this article: Gil-Setas A, Navascués-Ortega A, Beristain X. Spectinomycin in the treatment of gonorrhoea. Euro Surveill. 2010;15(19):pii=19568. Available online: http://www.eurosurveillance.org/ViewArticle.aspx?Articleld=19568

This article has been published on 13 May 2010

To the editor: We have read with interest the recent paper by Kubanova et al. in which they recommend the use of spectinomycin in case of difficulty to access ceftriaxone or in the presence of severe beta-lactam antimicrobial allergy [1]. Although we agree with most of the conclusions we would like to warn about the potential risks in cases of pharyngeal gonorrhoea. Spectinomycin is an aminoglycoside with poor saliva excretion. Probably due to changes in sexual behaviours the number of pharyngeal carriers of Neisseria gonorrhoeae is not anecdotal - papers report figures between $6 \%$ to $14 \%$ [2]. Moreover oral sex as only risk factor for urethral gonorrhoea is high ranging from $10 \%$ to $58 \%$ [2]. Lack of effective eradication of Neisseria gonorrhoeae from the pharynx with spectinomycin has been previously reported [3]. The Centers for Disease Control and Prevention (CDC) recommendations state that spectinomycin is useful for the treatment of patients who cannot tolerate cephalosporins and quinolones [4]. However, in the same guideline they recommended the use of a single dose of cefriaxone, 125 $\mathrm{mg}$ intramuscularly, or $500 \mathrm{mg}$ of oral ciprofloxacin (except for cases where high quinolone resistance is suspected) for pharynx eradication since spectinomycin is unreliable against pharyngeal infections. When spectinomycin is used, a pharyngeal negative culture three to five days after treatment should be the result [4]. In contrast, a single dose of two grammes of oral azithromycin would be considered an effective choice to cure non-complicated gonorrhoea from cervix, urethra and rectum and to eradicate the bacteria from the pharynx [5].

In conclusion we would point out that the use of a single dose of spectinomycin, though effective in the treatment of uncomplicated gonococcal infections from the cervix, urethra, and rectum, is less effective in the eradication of gonococci from the pharynx, thus allowing an important route for transmission of disease.
2. Janier M, Lassau F, Cassin I, Morel P. Pharyngeal gonorrhoea: the forgotten reservoir. Sex Transm Infect. 2003;79(4):345

3. Lindberg M, Ringertz 0 , Sandström E. Treatment of pharyngeal gonorrhoea due to beta-lactamase-producing gonococci. Br J Vener Dis. 1982;58(2):101-4.

4. Centers for Disease Control and Prevention (CDC). Sexually transmitted diseases treatment guidelines, 2006. MMWR Morb Mortal Wkly Rep. 2006;55(RR-11):1-94. Available from: http:// www.cdc.gov/mmwr/preview/mmwrhtml/rr5511a1.htm

5. Dan M, Poch F, Amitai Z, Gefen D, Shohat T. Pharyngeal Gonorrhoea in female sex workers: Response to a single 2-g dose of Azithromycin. Sex Transm Dis. 2006;33(8):512-5.

\section{References}

1. Kubanova A, Frigo N, Kubanov A, Sidorenko S, Lesnaya I, Polevshikova S, et al. The Russian gonococcal antimicrobial susceptibility programme (RU-GASP)-national resistance prevalence in 2007 and 2008, and trends during 2005-2008. Euro Surveill. 2010;15(14). pii=19533. Available from: http:// www.eurosurveillance.org/ViewArticle.aspx?Articleld=19533 